\title{
Gibberellin Inhibits Floral Initiation in the Perennial Woody Plant Jatropha curcas
}

\author{
Jialong $\mathrm{Li}^{1} \cdot$ Bang-Zhen $\mathrm{Pan}^{1} \cdot$ Longjian Niu $^{1} \cdot$ Mao-Sheng Chen ${ }^{1} \cdot$ Mingyong Tang $^{1} \cdot$ Zeng-Fu Xu $^{1}$
}

Received: 7 June 2017 / Accepted: 27 February 2018 / Published online: 8 March 2018

(c) The Author(s) 2018. This article is an open access publication

\begin{abstract}
Gibberellin (GA) is an important phytohormone and has been reported to promote flowering in annual and biennial plants, but may play an opposite role in woody perennial plants. In this study, the promoting or inhibiting effect of GA on floral initiation was investigated in Jatropha curcas L., a perennial woody plant, which has great potential as renewable energy plant due to the high oil content in the seed. We found that exogenous application of gibberellic acid $\left(\mathrm{GA}_{3}\right)$ inhibited flowering, whereas GA biosynthesis inhibitors promoted flowering. The promotive effect of the GA biosynthesis inhibitor paclobutrazol on floral initiation could be diminished by $\mathrm{GA}_{3}$ treatment. The expression levels of GA biosynthesis genes Jatropha GA 3-oxidase 3 (JCGA3ox3) and the GA receptor genes, Jatropha GA-INSENSITIVE DWARF 1C (JCGIDIC) were decreased, whereas a GA catabolism gene, Jatropha GA 2-oxidase 8 (JcGA2ox8), was elevated during floral transition. These results suggest that GA inhibits floral initiation in J. curcas.
\end{abstract}

Keywords Gibberellin · Gibberellin biosynthesis inhibitor · Paclobutrazol $\cdot$ Floral transition $\cdot$ Flowering $\cdot$ Biofuel $\cdot$ Physic nut

Jialong Li and Bang-Zhen Pan have contributed equally to this work.

Electronic supplementary material The online version of this article (https://doi.org/10.1007/s00344-018-9797-8) contains supplementary material, which is available to authorized users.

Zeng-Fu Xu

zfxu@xtbg.ac.cn; zengfu.xu@gmail.com

Jialong $\mathrm{Li}$

10710129@gmail.com

Bang-Zhen Pan

pbz@xtbg.org.cn

Longjian Niu

niulongjian@126.com

Mao-Sheng Chen

chenms@xtbg.org.cn

Mingyong Tang

tangmingyong@xtbg.ac.cn

1 Key Laboratory of Tropical Plant Resources and Sustainable Use, Xishuangbanna Tropical Botanical Garden, Chinese Academy of Sciences, Menglun, Mengla 666303, Yunnan, China

\section{Introduction}

Floral initiation occurs at a certain point after plants switch from the vegetative to the reproductive phase (Boss and others 2004). Floral formation is controlled strictly by the physiological state of the plant and environmental factors (Wellmer and Riechmann 2010). Gibberellin (GA) has been reported to control flowering in many plant species (Campos-Rivero and others 2017; Conti 2017). The ability of GA to promote floral initiation in plants has been established primarily for long-day and biennial species under conditions that would not normally permit flowering (Lang 1957). The exogenous application of GAs accelerates flowering in wildtype Arabidopsis, particularly during short days (Langridge 1957). The increase in bioactive GAs in the shoot apex contributes to the transition to reproductive development in, for example, the long-day grass Lolium temulentum (King and others 2006) and biennial species of sugar beet (Sorce and others 2002).

However, GA application did not result in the promotion of flowering in short-day plants (Lang 1957), and even has the opposite effect in woody perennial plants. For example, GA application inhibits floral initiation in avocado (Salazar-Garcia and Lovatt 1998), citrus (Muñoz-Fambuena 
and others 2012), sweet cherry (Lenahan and others 2006), peach (García-Pallas and others 2001), and Japanese plums (Gonzalez-Rossia and others 2006), whereas GA biosynthesis inhibitors have promoted reproductive development in mango (Winston 1992) and lychee (Menzel and Simpson 1990). Before the flowering of Mangifera indica, the concentration of GA in the shoot apical meristem is reduced (Tongumpai and others 1989). Boss and Thomas (2002) reported that in a dwarf, GA-insensitive mutant of grapevine, tendrils were converted to inflorescences, demonstrating that GA inhibited flowering in the grapevine. These studies indicated that GA plays different roles in annual, biennial and perennial plants. However, a recent report demonstrated that GA promotes the transition from vegetative to inflorescent development but inhibits flower formation in Arabidopsis (Yamaguchi and others 2014). The authors claimed that these results may help to explain the paradoxical observation that GA promotes flowering in most annual plants but inhibits floral initiation in some woody plants. However, the molecular mechanism of the GA-mediated inhibition of flowering in perennial woody plants is unknown.

Jatropha curcas L. (hereafter referred to as Jatropha) is a perennial and woody plant species belonging to the Euphorbiaceae family. Jatropha is widely distributed in tropical and sub-tropical regions and has great potential as renewable energy plant due to the high oil content in the seed (Koh and Mohd Ghazi 2011; Pandey and others 2012). However, the poor yield of this plant is an obstacle for its industrialization (Edrisi and others 2015; Sanderson 2009). Previous studies have tried to improve the seed yield by increasing female flower number per inflorescence or branching through the application of exogenous plant growth regulators and breeding transgenic plants (Abdelgadir and others 2010; Chen and others 2014; Ni and others 2015; Pan and others 2016; Pan and Xu 2011). However, another highly probable reason for the poor yield of this plant is that Jatropha has vigorous vegetative growth, whereas the reproductive growth is relatively poor (Ghosh and others 2010; Kochhar and others 2005). A feasible way to improve the seed yield is by promoting flowering.

Previous studies have reported that the GA biosynthesis inhibitor paclobutrazol (PAC) can effectively promote floral initiation of Jatropha (Ghosh and others 2010, 2011; Song and others 2013; Xu and others 2013). However, the effects on flowering of Jatropha by direct GA treatment and GA co-applied with a GA biosynthesis inhibitor have not been reported. In this study, we treated 4-year-old pruned and/or non-pruned Jatropha plants with GA and GA biosynthesis inhibitors separately or together to investigate the role of GA in the floral initiation of Jatropha. The expression profiles of GA biosynthesis, catabolism, and receptor genes in the shoot apex and inflorescence bud before and after floral initiation were also determined. The results in this study demonstrated that the exogenous application of GA inhibited flowering in Jatropha, while GA biosynthesis inhibitors promoted flowering. The results in this study could shed light on the mechanism of floral transition in Jatropha and/ or other woody plants.

\section{Materials and Methods}

\section{Plant Material}

Four-year-old Jatropha plants were grown at the Xishuangbanna Tropical Botanical Garden (XTBG, $21^{\circ} 54^{\prime} \mathrm{N}$, $101^{\circ} 46^{\prime} \mathrm{E}, 580 \mathrm{~m}$ in altitude) of the Chinese Academy of Sciences located in Mengla County, Yunnan Province, southwest China. The dry season lasts from November to April, and the rainy season lasts from May to October. The average rainfall, temperature, and relative humidity in April to July 2013, when the experiments were conducted, were $187.6 \mathrm{~mm}, 25.8{ }^{\circ} \mathrm{C}$, and $85.8 \%$, respectively (data from Xishuangbanna Station for Tropical Rain Forest Ecosystem Studies). The trees were planted $2.5 \mathrm{~m} \times 2.5 \mathrm{~m}$ apart. Treatments were performed on pruned and non-pruned Jatropha plants. Pruning was conducted in January 2013 during the period of dormancy.

\section{Plant Treatments and Data Collection}

\section{Application of $\mathrm{GA}_{3}$ to Pruned and Non-pruned Jatropha Plants}

When the new shoots of the pruned plants were $20 \mathrm{~cm}$ in length and the newly emerged leaves of the non-pruned plants had expanded, gibberellic acid $\left(\mathrm{GA}_{3}\right.$, Bio Basic Inc., Toronto, Ontario, Canada) was applied as a foliar spray to the entire pruned and non-pruned Jatropha trees at concentrations of $0,50,100,200,400,800,1200$, and $1600 \mu \mathrm{M}$ using a sprayer. Each $\mathrm{GA}_{3}$ working solution contained an equal volume of alcohol, which was used as a solvent for $\mathrm{GA}_{3}$. A surfactant, Tween-20 (Polysorbate-20, Shanghai Sangon Biological Engineering Technology \& Services Co., Ltd., China), was added to all the spray solutions at a concentration of $0.05 \%$. The spraying was consecutively conducted three times at 10-day interval. Phenotypic observations and data collection were performed 2 months after the treatment. For the non-pruned Jatropha plants, we randomly marked 30 branches per plant to estimate the total number of inflorescences and infructescences per branch. However, because the pruned Jatropha plants produced few flowers at that time, the ratio of the number of reproductive branches to the total number of branches was determined to represent the percentage of reproductive branches. 


\section{Application of GA Biosynthesis Inhibitors to Pruned} Jatropha Plants

GA biosynthesis inhibitors, chlormequat chloride (CCC), mepiquat chloride ( $N$-dimethylpiperidinium chloride, DPC) and PAC, were supplied as wettable powders (products of Zhengzhou Century Technology Co., Ltd., China), the purities of which were 98,97 , and $15 \%$, respectively. When the new shoots of the pruned plants were $20 \mathrm{~cm}$ in length, dilute suspensions of CCC, DPC, and PAC were sprayed onto the entire pruned Jatropha plants at concentrations of 500, 1500, 3000 , and $4500 \mathrm{mg} / \mathrm{l}$ with Tween-20 at a concentration of $0.05 \%$. Control plants were sprayed with distilled water containing $0.05 \%$ Tween- 20 . The spraying was consecutively conducted twice with a 10-day interval. Phenotypic observations and data collection were performed 2 months after the treatments. The percentages of reproductive branches were then determined.

\section{Co-application of GA and PAC to the Pruned Jatropha Plants}

The soil application of PAC ( $8 \mathrm{~g}$ per plant) was carried out during the period of dormancy according to Ghosh's method (Ghosh and others 2010). Various concentrations of $\mathrm{GA}_{3}$ were sprayed onto PAC-treated plants when the new shoots of the pruned plants were $20 \mathrm{~cm}$ in length. The $\mathrm{GA}_{3}$ treatments were consecutively conducted three times at 10-day interval. Phenotypic observations and data collection were performed 2 months after the treatments. We randomly marked 30 branches per plant to estimate the total number of inflorescences and infructescences per branch. The percentages of reproductive branches were also determined.

\section{RNA Extraction and Quantitative Real-Time PCR (qRT-PCR)}

For the expression profile analysis of GA biosynthesis and catabolism genes, the shoot apex and inflorescence bud before and after floral initiation of 4-year-old Jatropha plants were sampled and immediately frozen in liquid nitrogen and then maintained at $-80^{\circ} \mathrm{C}$. Total RNA was isolated according to the method reported by Ding and others (2008). The RNA was quantified using a NanoDrop 2000 spectrophotometer (Thermo Fisher Scientific, Wilmington, USA). Approximately one $\mu \mathrm{g}$ of total RNA was used for cDNA synthesis according to the method described in the Takara PrimeScript ${ }^{\mathrm{TM}}$ RT Reagent Kit (Takara Biotechnology, Dalian, China). qRT-PCR was performed with the LightCycler 480 II (Roche, Switzerland) using three independent biological replicates and three technical replicates for each sample. The data were analyzed using the $2^{-\Delta \Delta C_{T}}$ method as described by Livak and Schmittgen (2001). The transcript levels of specific genes were normalized using JCACTIN (Zhang and others 2013). The primers used are listed in Supplementary Table S1.

\section{Statistical Analysis}

The data were analyzed using the Statistical Product and Service Solutions software (SPSS Inc., Chicago, IL, USA, version 16.0). Differences among the means were determined using a one-way ANOVA with Tukey's or Tamhane's post hoc tests $(p<0.05)$. Graphs were drawn with SigmaPlot (version 12.5; Systat Software, Point Richmond, CA).

\section{Results}

\section{$\mathrm{GA}_{3}$ Treatments Decreased the Percentages of Reproductive Branches and the Total Number of Inflorescence and Infructescence}

To study the effect of GA treatment on Jatropha floral initiation, different concentrations of $\mathrm{GA}_{3}$ were applied to pruned and non-pruned Jatropha plants. The results showed that $\mathrm{GA}_{3}$ treatment profoundly inhibited the floral initiation of Jatropha in proportion to the concentration of $\mathrm{GA}_{3}$ (Fig. 1). In the pruned plants, the percentages of reproductive branches were significantly reduced in four treatments $(100,800,1200,1600 \mu \mathrm{M})$, but no significant difference was found among the four treatments (Fig. 1c). In the non-pruned plants, the total number of inflorescences and infructescences per branch was significantly decreased from 1.7 (control) to $0.5\left(800 \mu \mathrm{M} \mathrm{GA}_{3}\right)$, which was not significantly different from that of the $\mathrm{GA}_{3}$ concentrations $>800 \mu \mathrm{M}$ (Fig. 1b, d).

\section{Treatment with GA Biosynthesis Inhibitors Increased the Percentages of Reproductive Branches}

Three GA biosynthesis inhibitors, CCC, DPC, and PAC were applied at various concentrations to the pruned Jatropha plants. The results indicated that all three inhibitor treatments can improve flowering in Jatropha. The percentage of reproductive branches was significantly increased after treatments with PAC and DPC compared to the control plants and was not different among the four concentrations in each group. In the CCC treatment group, the maximum value was obtained at the concentration of $1500 \mathrm{mg} / \mathrm{l}$, which was significantly higher than that obtained at the concentrations of $500 \mathrm{mg} / \mathrm{l}$ and $4500 \mathrm{mg} / \mathrm{l}$ (Fig. 2). The percentage was $8.2 \%$ in the controls and was increased to $53.8,43.5$, and $45.0 \%$ respectively, after the PAC $(3000 \mathrm{mg} / \mathrm{l})$, DPC $(1500 \mathrm{mg} / \mathrm{l})$, and CCC (1500 mg/l) treatments (Fig. 2). The highest percentage among the three groups of treatments was obtained at $3000 \mathrm{mg} / \mathrm{l}$ in PAC treatment group (the purity 

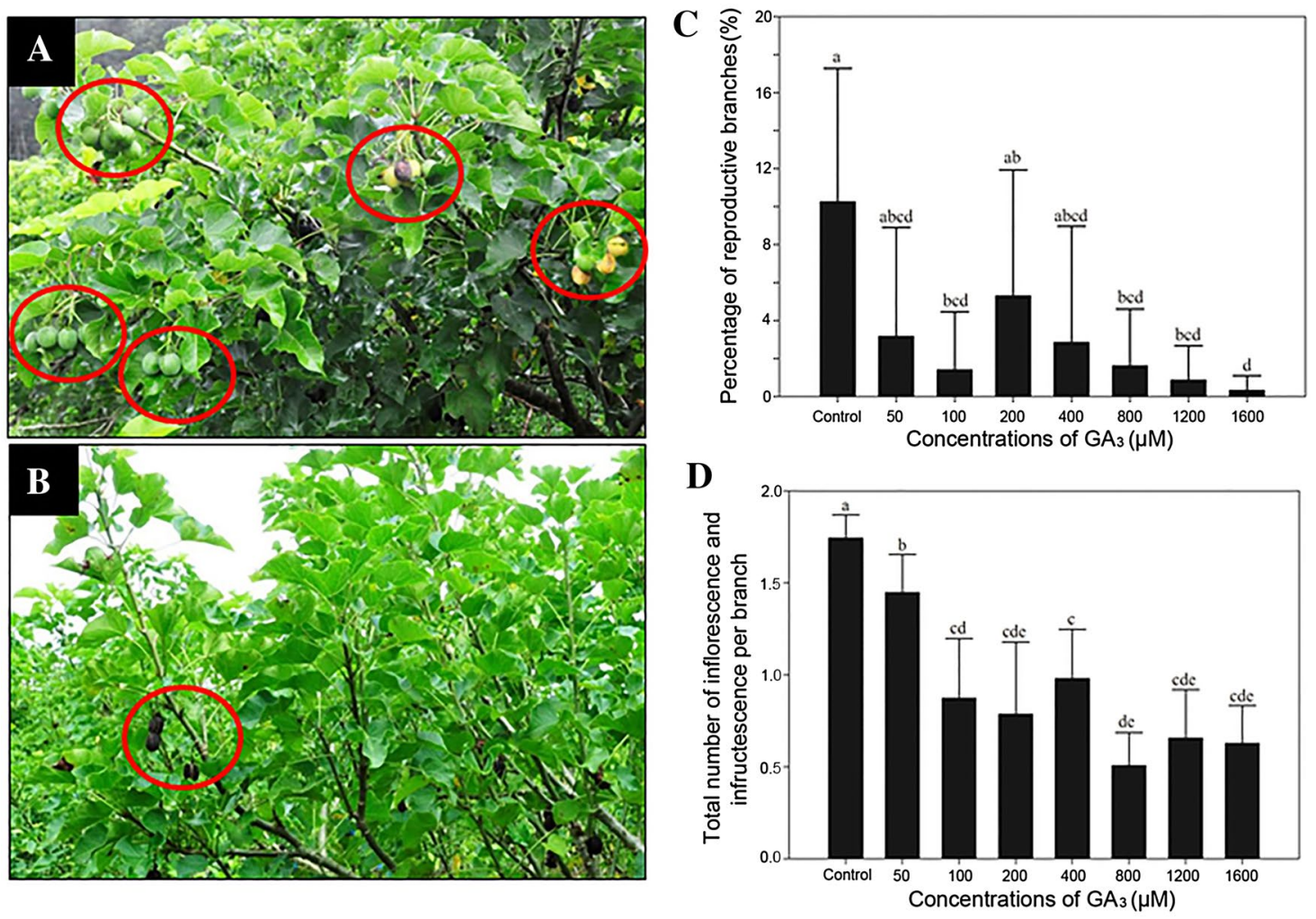

Fig. $1 \mathrm{GA}_{3}$ inhibits flowering in Jatropha. a Control plant; b $\mathrm{GA}_{3}$-treated plant $(800 \mu \mathrm{M})$; $\mathbf{c}$ effect of $\mathrm{GA}_{3}$ on percentage of reproductive branches in pruned Jatropha plants $(n=21-30)$; d effect of $\mathrm{GA}_{3}$ on total number of inflorescence and infructescence per branch

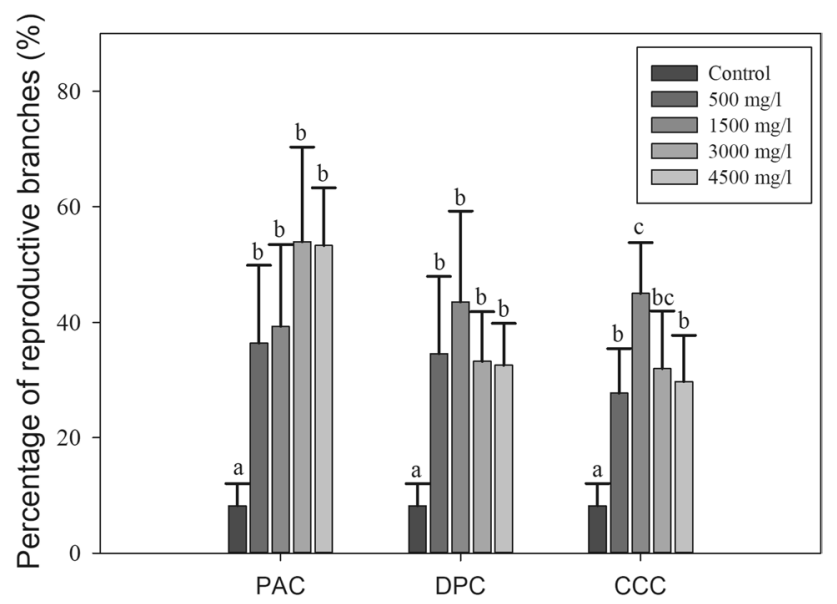

Fig. 2 GA biosynthesis inhibitors promote flowering in Jatropha. $P A C$ paclobutrazol, DPC mepiquat chloride, $C C C$ chlormequat chloride. Values are means \pm standard deviations $(n=15-20$ plants). Different letters above the error bar indicate significant difference for $p<0.05$

of the PAC compound was $15 \%$ ), demonstrating that PAC is more active than DPC and CCC.

in non-pruned Jatropha plants. Values are means \pm standard deviations ( $n=15-20$ plants). Different letters above the error bar in (c) and (d) indicate significant difference for $p<0.05$

\section{$\mathrm{GA}_{3}$ Treatment Diminished the Promotional Effect of PAC on Floral Initiation}

To further confirm the inhibition of floral initiation by GA in Jatropha, the co-application of $\mathrm{GA}_{3}$ and the GA biosynthesis inhibitor (PAC) was conducted in Jatropha plants. The pruned plants, which are more sensitive to PAC than non-pruned plants (Ghosh and others 2010; Song and others 2013), were chosen for these experiments. The percentage of reproductive branches was profoundly increased from $10.3 \%$ in the control plants to $54.7 \%$ after PAC treatment alone (Fig. 3a, b, e). The ability of PAC to improve flowering was diminished by the exogenous application of $\mathrm{GA}_{3}$ (Fig. 3c, $\mathrm{d}, \mathrm{f})$. The percentage of reproductive branches was reduced with increasing concentrations of $\mathrm{GA}_{3}$, reaching the lowest at $1600 \mu \mathrm{M}$ of $\mathrm{GA}_{3}(6.9 \%)$, which was not significantly different from the control plants (Fig. 3e). The total number of inflorescences and infructescences per branch exhibited the same trend (Fig. 3f), and was increased profoundly from 0.15 in the controls to 0.60 per branch after PAC treatment alone but decreased significantly to 0.05 per branch after the exogenous application of $\mathrm{GA}_{3}$ at $1600 \mu \mathrm{M}$ (Fig. 3f). 

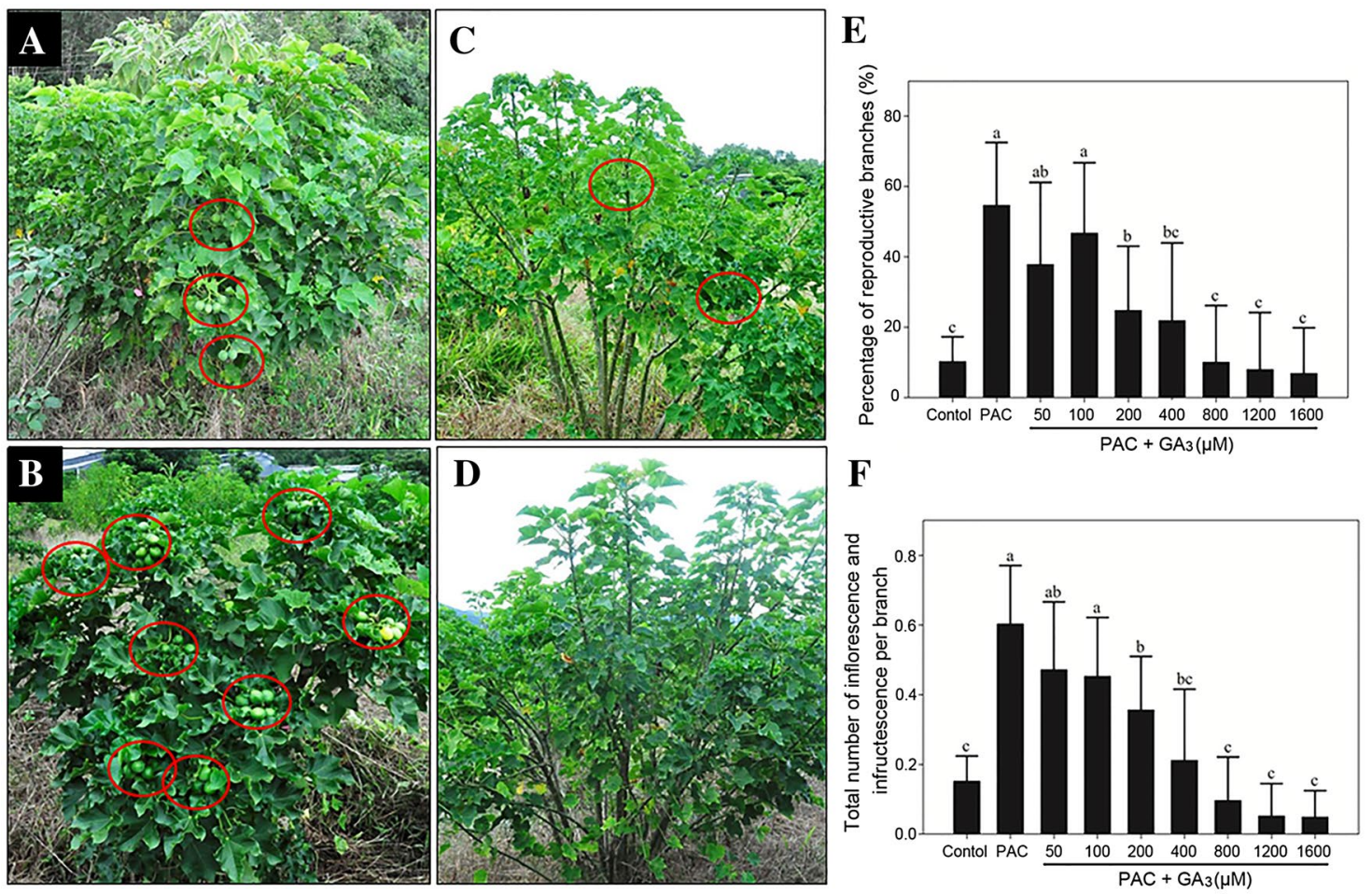

Fig. $3 \mathrm{GA}_{3}$ reverses the promotive effect of PAC on flowering in Jatropha. a Control plant; b PAC-treated plant; c plant treated with $\mathrm{PAC}+\mathrm{GA}_{3}(400 \mu \mathrm{M}) ; \mathbf{d}$ plant treated with $\mathrm{PAC}+\mathrm{GA}_{3}(1600 \mu \mathrm{M})$; the percentage of reproductive branches (e) and the total number of

\section{Expression Analysis of GA Biosynthesis, Catabolism and Receptor Genes During Floral Initiation}

To determine probable changes in the level of endogenous GA during floral initiation, the expression profiles of GA biosynthesis, catabolism and receptor genes (Hedden and Phillips 2000) were analyzed in the shoot apex and inflorescence buds before and after floral initiation. Sequences of Jatropha homologues of genes encoding two GA biosynthesis genes GA 20-oxidase 1 (JcGA20oxl) and GA 3-oxidase 3 (JcGA3ox3), four catabolism genes GA 2-oxidase 2/4/6/8 (JCGA2ox2/4/6/8), and two GA receptor genes GA-INSENSITIVE DWARFIB (JcGIDIB) and JCGIDIC, were indentified from the Jatropha Genome Database (http://www.kazus a.or.jp/jatropha/, (Hirakawa and others 2012)), and were used for phylogenetic analysis together with those of the Arabidopsis genes (The Arabidopsis Information Resources; http://www.arabidopsis.org) (Figure S1). qRT-PCR analysis (Fig. 4) revealed that $J c G A 3 o x 3$, which catalyze the final step of GA biosynthesis (Hedden and Phillips 2000) was down-regulated in the inflorescence bud after floral initiation compared to their levels in the shoot apex before floral initiation, whereas the expression level of another biosynthetic gene JcGA20oxl showed no significant difference. Among the four GA catabolism genes $J_{c} G A 2 o x 2$, JcGA2ox4, inflorescences and infructescences per branch (f) were decreased by $\mathrm{GA}_{3}$ treatment in PAC-treated plants; values are means \pm standard deviations ( $n=30$ plants). Different letters above the error bar in (e) and (f) indicate significant difference for $p<0.05$

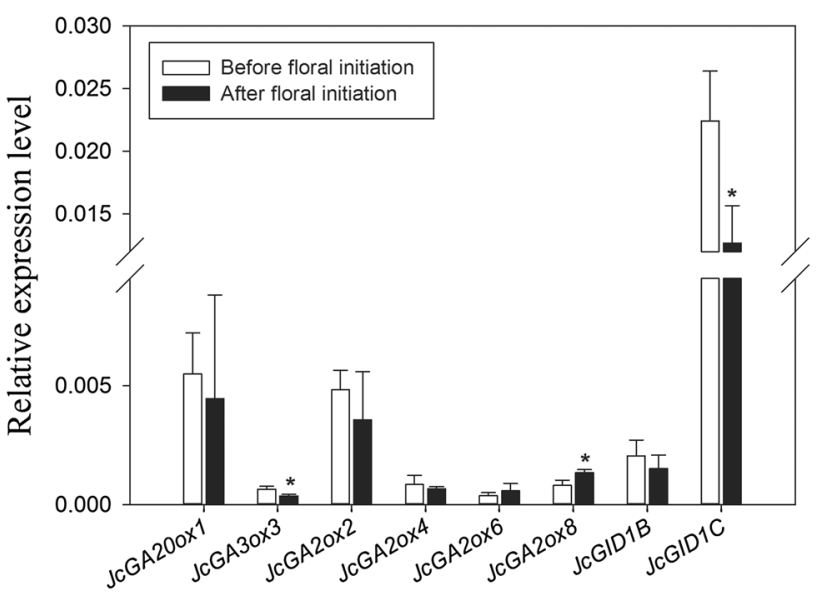

Fig. 4 Quantification of the expression of GA biosynthesis, catabolism and receptor genes during floral transition by qRT-PCR. JcGA20ox1, Jatropha GA 20-oxidase 1; JcGA3ox3, Jatropha GA 3-oxidase 3; JcGA2ox2, Jatropha GA 2-oxidase 2; JcGA2ox4, Jatropha GA 2-oxidase 4; JcGA2ox6, Jatropha GA 2-oxidase 6; JcGA2ox8, Jatropha GA 2-oxidase 8; JcGID1B, Jatropha GAINSENSITIVE DWARF1B; JCGID1C, Jatropha GA-INSENSITIVE $D W A R F 1 C$. The levels of the detected amplicons were normalized using the amplified product of JCACTIN. Values are means \pm standard deviations $(n=3)$. *Statistically significant at the $5 \%$ level 
$J_{c} G A 2 o x 6$, and $J_{c} G A 2 o x 8$, only the expression of $J_{c} G A 2 o x 8$ was up-regulated during floral initiation (Fig. 4). We also detected the expression levels of two GA receptor genes (Murase and others 2008) encoding Jatropha JcGID1B and JcGID1C (Ni and others 2017), which undergo a conformational changes after the reception of bioactive GA and then binding to DELLA to form the GA-GID1-DELLA complex, which stimulates the degradation of DELLAs by the $26 \mathrm{~S}$ proteasome, thereby initiating the signal transduction cascade (Sun 2011). JcGIDIC was down-regulated during the floral transition, whereas the expression level of JcGID1B was not significantly affected (Fig. 4).

\section{Discussion}

GA has been previously reported to possess an inhibitory role in the floral transition of certain perennials (Wilkie and others 2008). In this study, the results suggested that the exogenous application of GA inhibited floral initiation in Jatropha. Consistently, we found that the expression level of a GA biosynthesis gene $J c G A 3 o x 3$ was reduced, whereas that of $J_{c} G A 2 o x 8$, a GA degradation gene was elevated after floral initiation (Fig. 4), indicating a decrease in endogenous GA contents during floral transition. And the down-regulated expression of the GA receptor gene $J c G I D I C$ after floral initiation (Fig. 4), which could result in a decreased GA sensitivity, may further reinforce the regulation of GAresponsive genes involved in floral initiation (CamposRivero and others 2017; Conti 2017; Davière and Achard 2013). The result is in agreement with previous studies of other woody plant species. In $M$. indica, the GA content in shoot apical meristem (SAM) was decreased during the floral transition (Chen 1987). In rose, a decrease in the GA content in SAM was a prerequisite for floral transition (Guo and others 2017; Roberts and others 1999). Furthermore, the variation of GA content was correlate with the expression of GA metabolism genes in rose during floral transition (Guo and others 2017; Remay and others 2009). In both non-recurrent and recurrent blooming rose, GA biosynthesis gene RoGA20ox was transiently repressed before floral initiation, whereas the expression of GA degradation gene RoGA2ox increased (Remay and others 2009). Recently, Guo and others (2017) also showed that in recurrent flowering Rosa chinensis 'Old Blush,' a common ancestor of modern roses, GA biosynthesis genes, such as ent-copalyl diphosphate synthase (CPS), ent-kaurene oxidase (KO), GA20oxl, and $G A 3 O x$, were down-regulated from vegetative meristem to pre-floral meristem, while GA2ox was up-regulated. However, the expression of GA receptor gene RoGIDl in rose was regulated differently between the non-recurrent and the recurrent blooming rose (Remay and others 2009). In nonrecurrent rose whose flowering was inhibited by exogenous applications of $\mathrm{GA}_{1}$ and $\mathrm{GA}_{3}$ (Roberts and others 1999), RoGIDl was expressed at the same level during the floral process; whereas in recurrent rose whose flowering was not inhibited by exogenous applications of GA (Roberts and others 1999), RoGIDI was up-regulated after the floral initiation (Remay and others 2009). In this study, JcGIDIC, one of the two GA receptor genes in Jatropha whose flowering was inhibited by exogenous applications of $\mathrm{GA}_{3}$ as shown above, was down-regulated during the floral transition, whereas another member $J c G I D 1 B$ remained stable (Fig. 4). Therefore, the molecular mechanism of GA-mediated inhibition of flowering in woody plants remains elusive.

In Arabidopsis, the elevated levels of endogenous $\mathrm{GA}_{4}$ or exogenous application of $\mathrm{GA}_{3}$ promoted the termination of vegetative phase and increase the expression of $L E A F Y$ $(L F Y)$, which induces the expression of the GA catabolism enzyme EUI-LIKE P450 Al (ELAI), resulting in a decrease in GA content (Yamaguchi and others 2014). The subsequent reduction in the GA levels allows the DELLA protein to bind SPL, inducing API expression and promoting the transformation of the lateral primordia into flowers (Yamaguchi and others 2014). The ability of GA to promote the transition from the juvenile to the adult growth phase was observed in several species (Mutasa-Göttgens and Hedden 2009). A previous study also has reported that GA promoted the flowering of Arabidopsis by activating the LEAFY (LFY) promoter (Blázquez and others 1998). However, in Jatropha, the expression of Jatropha LFY (JcLFY) was not induced but rather was repressed between 3 and $48 \mathrm{~h}$ after GA application both in the shoot apex and the inflorescence bud (Tang and others 2016a). Overexpressing JcLFY in Arabidopsis causes significant early flowering while the overexpression of this gene in Jatropha causes slight early flowering, only 2 months earlier than the WT plant (Tang and others 2016a), which has also been observed in apple (Flachowsky and others 2010) and poplar (Rottmann and others 2000). In addition, a transgenic Jatropha with co-suppressed JcLFY did not exhibit significantly late flowering (Tang and others 2016a). These results suggested that $J c L F Y$ is not a key flowering promoter in Jatropha. Thus, although GA application repressed $J C L F Y$ expression, the GA-mediated inhibition of flowering in Jatropha may be unrelated to JcLFY. Moreover, the overexpression of $J c A P 1$ did not cause early flowering in Jatropha but did cause early flowering in Arabidopsis (Tang and others 2016b), as has also been observed in aspen (Azeez and others 2014). Thus, the molecular mechanism of the GA-regulated floral transition in woody plants, at least in Jatropha, is complicated and may be different from that in Arabidopsis, which may involve multiple factors (Albani and Coupland 2010).

Our results in this report provide strong evidence that GA inhibits flowering in woody Jatropha. However, additional experiments including detection of the GA contents during 
floral initiation by new sensitive methods for GA quantification (Deng and others 2017; Li and others 2016, 2017), expression analysis of DELLA and other genes in the GA signaling pathway (Davière and Achard 2013), and modulation of GA contents in shoot apex by transgene expression, are required to elucidate the cellular and molecular mechanisms underlying GA regulation of floral initiation in Jatropha. In addition, several studies with adult Jatropha plants showed that GA biosynthesis inhibitor PAC, rather than GA, promoted reproductive development (Ghosh and others 2011, 2010; Song and others 2013; Xu and others 2013), which seems contrary to the role of GA in promoting the transition from vegetative to reproductive development in Arabidopsis (Yamaguchi and others 2014). Therefore, further studies with Jatropha seedlings are required to investigate the role of GA in the transition from juvenile to adult phase.

Acknowledgements The authors gratefully acknowledge the Xishuangbanna Station for Tropical Rain Forest Ecosystem Studies for granting permission to use the data presented in this study and the Central Laboratory of the Xishuangbanna Tropical Botanical Garden for providing research facilities.

Author Contributions Z-FX, JL, and B-ZP designed experiments. JL and B-ZP analyzed the data and drafted the work. JL and LN carried out experiments, Z-FX, M-SC, and MT critically revised the manuscript.

Funding This work was supported by funding from the National Natural Science Foundation of China (31500500 and 31370595), the Natural Science Foundation of Yunnan Province (2016FB033), and the Program of Chinese Academy of Sciences (ZSZC-014, 2017XTBG-T02).

Open Access This article is distributed under the terms of the Creative Commons Attribution 4.0 International License (http://creativeco mmons.org/licenses/by/4.0/), which permits unrestricted use, distribution, and reproduction in any medium, provided you give appropriate credit to the original author(s) and the source, provide a link to the Creative Commons license, and indicate if changes were made.

\section{References}

Abdelgadir H, Jäger A, Johnson S, Van Staden J (2010) Influence of plant growth regulators on flowering, fruiting, seed oil content, and oil quality of Jatropha curcas. S Afr J Bot 76:440-446

Albani MC, Coupland G (2010) Comparative analysis of flowering in annual and perennial plants. Curr Top Dev Biol 91:323-348

Azeez A, Miskolczi P, Tylewicz S, Bhalerao RP (2014) A tree ortholog of APETALA1 mediates photoperiodic control of seasonal growth. Curr Biol 24:717-724

Blázquez MA, Green R, Nilsson O, Sussman MR, Weigel D (1998) Gibberellins promote flowering of Arabidopsis by activating the LEAFY promoter. Plant Cell 10:791-800

Boss PK, Thomas MR (2002) Association of dwarfism and floral induction with a grape 'green revolution' mutation. Nature 416:847-850
Boss PK, Bastow RM, Mylne JS, Dean C (2004) Multiple pathways in the decision to flower: enabling, promoting, and resetting. Plant Cell 16:S18-S31

Campos-Rivero G, Osorio-Montalvo P, Sánchez-Borges R, Us-Camas R, Duarte-Aké F, De-la-Peña C (2017) Plant hormone signaling in flowering: an epigenetic point of view. J Plant Physiol 214:16-27. https://doi.org/10.1016/j.jplph.2017.03.018

Chen W-S (1987) Endogenous growth substances in relation to shoot growth and flower bud development of mango. J Am Soc Hortic Sci 112:360-363

Chen MS, Pan BZ, Wang GJ, Ni J, Niu L, Xu ZF (2014) Analysis of the transcriptional responses in inflorescence buds of Jatropha curcas exposed to cytokinin treatment. BMC Plant Biol 14:318

Conti L (2017) Hormonal control of the floral transition: can one catch them all? Dev Biol 430:288-301. https://doi.org/10.1016/j.ydbio .2017.03.024

Davière J-M, Achard P (2013) Gibberellin signaling in plants. Development 140:1147-1151. https://doi.org/10.1242/dev.087650

Deng T, Wu D, Duan C, Yan X, Du Y, Zou J, Guan Y (2017) Spatial profiling of gibberellins in a single leaf based on microscale matrix solid-phase dispersion and precolumn derivatization coupled with ultraperformance liquid chromatography-tandem mass spectrometry. Anal Chem 89:9537-9543. https://doi.org/10.1021/ acs.analchem.7b02589

Ding L-W, Sun Q-Y, Wang Z-Y, Sun Y-B, Xu ZF (2008) Using silica particles to isolate total RNA from plant tissues recalcitrant to extraction in guanidine thiocyanate. Anal Biochem 374:426-428

Edrisi SA et al (2015) Jatropha curcas L.: a crucified plant waiting for resurgence. Renew Sustain Energy Rev 41:855-862

Flachowsky H, Hättasch C, Höfer M, Peil A, Hanke M-V (2010) Overexpression of $L E A F Y$ in apple leads to a columnar phenotype with shorter internodes. Planta 231:251-263

García-Pallas I, Val J, Blanco A (2001) The inhibition of flower bud differentiation in 'Crimson Gold' nectarine with GA 3 as an alternative to hand thinning. Sci Hortic 90:265-278

Ghosh A, Chikara J, Chaudhary DR, Prakash AR, Boricha G, Zala A (2010) Paclobutrazol arrests vegetative growth and unveils unexpressed yield potential of Jatropha curcas. J Plant Growth Regul 29:307-315

Ghosh A, Chikara J, Chaudhary DR (2011) Diminution of economic yield as affected by pruning and chemical manipulation of Jatropha curcas L. Biomass Bioenergy 35:1021-1029. https://doi. org/10.1016/j.biombioe.2010.11.019

Gonzalez-Rossia D, Juan M, Reig C, Agusti M (2006) The inhibition of flowering by means of gibberellic acid application reduces the cost of hand thinning in Japanese plums (Prunus salicina Lindl.). Sci Hortic 110:319-323

Guo X et al (2017) Transcriptome of the floral transition in Rosa chinensis 'Old Blush'. BMC Genomics 18:199. https://doi. org/10.1186/s12864-017-3584-y

Hedden P, Phillips AL (2000) Gibberellin metabolism: new insights revealed by the genes. Trends Plant Sci 5:523-530

Hirakawa $\mathrm{H}$ et al (2012) Upgraded genomic information of Jatropha curcas L. Plant Biotechnol 29:123-130

King RW et al (2006) Regulation of flowering in the long-day grass Lolium temulentum by gibberellins and the FLOWERING LOCUS $T$ gene. Plant Physiol 141:498-507. https://doi.org/10.1104/ pp.106.076760

Kochhar S, Kochhar V, Singh S, Katiyar R, Pushpangadan P (2005) Differential rooting and sprouting behaviour of two Jatropha species and associated physiological and biochemical changes. Curr Sci 89:936-939

Koh MY, Mohd Ghazi TI (2011) A review of biodiesel production from Jatropha curcas L. oil. Renew Sustain Energy Rev 15:2240-2251

Lang A (1957) The effect of gibberellin upon flower formation. Proc Natl Acad Sci USA 43:709-717 
Langridge J (1957) Effect of day-length and gibberellic acid on the flowering of Arabidopsis. Nature 180:36-37

Lenahan OM, Whiting MD, Elfving DC (2006) Gibberellic acid inhibits floral bud induction and improves 'Bing' sweet cherry fruit quality. HortScience 41:654-659

Li D, Guo Z, Chen Y (2016) Direct derivatization and quantitation of ultra-trace gibberellins in sub-milligram fresh plant organs. Mol Plant 9:175-177. https://doi.org/10.1016/j.molp.2015.07.001

Li D, Guo Z, Liu C, Li J, Xu W, Chen Y (2017) Quantification of near-attomole gibberellins in floral organs dissected from a single Arabidopsis thaliana flower. Plant J 91:547-557. https://doi. org/10.1111/tpj. 13580

Livak KJ, Schmittgen TD (2001) Analysis of relative gene expression data using real-time quantitative PCR and the $2^{-\Delta \Delta C T}$ method. Methods 25:402-408

Menzel C, Simpson D (1990) Effect of paclobutrazol on growth and flowering of lychee (Litchi chinensis). Aust J Exp Agric 30:131-137

Muñoz-Fambuena N, Mesejo C, González-Mas MC, Iglesias DJ, Primo-Millo E, Agustí M (2012) Gibberellic acid reduces flowering intensity in sweet orange [Citrus sinensis (L.) Osbeck] by repressing CiFT gene expression. J Plant Growth Regul 31:529-536

Murase K, Hirano Y, Sun T-p, Hakoshima T (2008) Gibberellininduced DELLA recognition by the gibberellin receptor GID1. Nature 456:459-463

Mutasa-Göttgens E, Hedden P (2009) Gibberellin as a factor in floral regulatory networks. J Exp Bot 60:1979-1989

Ni J, Gao C, Chen MS, Pan BZ, Ye K, Xu ZF (2015) Gibberellin promotes shoot branching in the perennial woody plant Jatropha curcas. Plant Cell Physiol 56:1655-1666

Ni J, Zhao M, Chen M, Pan B, Tao Y, Xu Z (2017) Comparative transcriptome analysis of axillary buds in response to the shoot branching regulators gibberellin A3 and 6-benzyladenine in Jatropha curcas. Sci Rep 7:11417

Pan BZ, Xu ZF (2011) Benzyladenine treatment significantly increases the seed yield of the biofuel plant Jatropha curcas. J Plant Growth Regul 30:166-174

Pan BZ, Luo Y, Song L, Chen MS, Li J, Xu ZF (2016) Thidiazuron increases fruit number in the biofuel plant Jatropha curcas by promoting pistil development. Ind Crops Prod 81:202-210

Pandey VC, Singh K, Singh JS, Kumar A, Singh B, Singh RP (2012) Jatropha curcas: a potential biofuel plant for sustainable environmental development. Renew Sustain Energy Rev 16:2870-2883

Remay A, Lalanne D, Thouroude T, Le Couviour F, Hibrand-Saint Oyant L, Foucher F (2009) A survey of flowering genes reveals the role of gibberellins in floral control in rose. Theor Appl Genet 119:767-781. https://doi.org/10.1007/s00122-009-1087-1

Roberts AV, Blake PS, Lewis R, Taylor JM, Dunstan DI (1999) The effect of gibberellins on flowering in roses. J Plant Growth Regul 18:113-119. https://doi.org/10.1007/p100007058
Rottmann WH et al (2000) Diverse effects of overexpression of $L E A F Y$ and PTLF, a poplar (Populus) homolog of LEAFYIFLORICAULA, in transgenic poplar and Arabidopsis. Plant J 22:235-245

Salazar-Garcia S, Lovatt CJ (1998) GA3 application alters flowering phenology of 'Hass' avocado. J Am Soc Hortic Sci 123:791-797

Sanderson K (2009) Wonder weed plans fail to flourish. Nature 461:328

Song J, Chen M-S, Li J-L, Niu L-J, Xu Z-F (2013) Effects of soilapplied paclobutrazol on the vegetative and reproductive growth of biofuel plant Jatropha curcas. Plant Divers Resour 35:173-179

Sorce C, Stevanato P, Biancardi E, Lorenzi R (2002) Physiological mechanisms of floral stem elongation (bolting) control in sugar beet (Beta vulgaris ssp. vulgaris L.). Agroindustria 1:87-91

Sun T-p (2011) The molecular mechanism and evolution of the GA-GID1-DELLA signaling module in plants. Curr Biol 21:R338-R345

Tang MY, Tao YB, Fu QT, Song YL, Niu LJ, Xu ZF (2016a) An ortholog of $L E A F Y$ in Jatropha curcas regulates flowering time and floral organ development. Sci Rep 6:37306. https://doi. org/10.1038/srep37306

Tang MY, Tao YB, Xu ZF (2016b) Ectopic expression of Jatropha curcas APETALA1 (JcAPl) caused early flowering in Arabidopsis, but not in Jatropha. PeerJ 4:e1969. https://doi.org/10.7717/ peerj.1969

Tongumpai P, Jutamanee K, Sethapakdi R, Subhadrabandhu S (1989) Variation in level of gibberellin-like substances, during vegetative growth and flowering of mango cv. Khiew Sawoey. III Int Mango Symp 291:105-108

Wellmer F, Riechmann JL (2010) Gene networks controlling the initiation of flower development. Trends Genet 26:519-527

Wilkie JD, Sedgley M, Olesen T (2008) Regulation of floral initiation in horticultural trees. J Exp Bot 59:3215-3228

Winston E (1992) Evaluation of paclobutrazol on growth, flowering and yield of mango cv. Kensington Pride. Aust J Exp Agric 32:97-104

Xu G, Luo R, Yao Y (2013) Paclobutrazol improved the reproductive growth and the quality of seed oil of Jatropha curcas. J Plant Growth Regul 32:875-883. https://doi.org/10.1007/s0034 4-013-9353-5

Yamaguchi N, Winter CM, Wu M-F, Kanno Y, Yamaguchi A, Seo M, Wagner D (2014) Gibberellin acts positively then negatively to control onset of flower formation in Arabidopsis. Science 344:638-641

Zhang L, He L-L, Fu Q-T, Xu Z-F (2013) Selection of reliable reference genes for gene expression studies in the biofuel plant Jatropha curcas using real-time quantitative PCR. Int J Mol Sci 14:24338-24354. https://doi.org/10.3390/ijms141224338 